\title{
A importância da gestão democrática e participativa nas escolas públicas da Baixada
}

\section{Fluminense}

The importance of democratic and participative management in public schools in the Baixada

\author{
Fluminense region
}

La importância de la gestion democrática y participativa em las escuelas públicas de la comarca Baixada Fluminense

Thayná Vieira de Oliveira ORCID: https://orcid.org/0000-0002-3548-0396 Universidade Estácio de Sá, Brasil E-mail: vieirathayna6@gmail.com

Melissa Ferreira Reis ORCID: https://orcid.org/0000-0002-6707-3816 Universidade Estácio de Sá, Brasil E-mail: melissaferreirareis@gmail.com

Caíque Pereira Ribeiro ORCID: https://orcid.org/0000-0002-0491-0525 Centro Universitário Carioca, Brasil E-mail: caique_p2@outlook.com

Ana Greyce Lima da Silva de Mesquita ORCID: https://orcid.org/0000-0002-7057-5067 Universidade Estácio de Sá, Brasil E-mail: pedagoga.anagreyce@gmail.com

Alexandro de Oliveira ORCID: https://orcid.org/0000-0003-2168-3552 Universidade Estácio de Sá, Brasil E-mail: alexemarcia@gmail.com

Rosangela Corrêa Pereira Ribeiro ORCID: https://orcid.org/0000-0002-0114-401X Universidade Salgado de Oliveira, Brasil E-mail: rosangelacpr@hotmail.com

Tathiana Lopes Pontes

ORCID: https://orcid.org/0000-0002-7118-0411 Centro Universitário da Cidade, Brasil E-mail: tathiana.l.pontes@hotmail.com

\section{Resumo}

A ênfase deste estudo é refletir sobre a importância de uma gestão democrática e participativa na Escola Pública, em que o gestor tem papel primordial para fazer uma escola interativa e agradável com o objetivo de uma educação de qualidade. Este artigo tem como objetivo analisar a importância desta gestão para construção de um conhecimento de qualidade nas escolas públicas da Baixada Fluminense. Realizou-se uma pesquisa bibliográfica e pesquisa de campo com entrevistas, considerando as contribuições de autores como Luck (2005 e 2017), Veiga (1997), Pereira (2018), Santos (2021), Fogaça (2021), entre outros. A inserção de uma gestão democrático-participativa ainda é um processo em andamento, mesmo sendo um viés da política pública, ainda há certo desafio nesta implantação. Considera-se a relevância de um processo educativo participativo para que um ensino-aprendizagem aconteça com qualidade nas escolas públicas, pois são agentes primordiais no processo de formação da educação, alcança-se assim uma equipe unida, responsáveis mais interativos com os profissionais de educação da escola e com a formação do educando e de toda comunidade escolar.

Palavras-chave: Gestão; Democracia; Participativo; Pública.

\begin{abstract}
The emphasis of this study is to reflect on the importance of a democratic and participative management in the Public School, in which the manager has a fundamental role to make an interactive and pleasant school with the objective of a quality education. This article aims to analyze the importance of this management for building quality knowledge in public schools in the Baixada Fluminense. A bibliographic and field research was carried out, considering the contributions of authors such as Luck (2005 and 2017), Veiga (1997), Pereira (2018), Santos (2021),
\end{abstract}


Fogaça (2021), among others. The insertion of a democratic-participative management is still an ongoing process, even though it is a public policy bias, there is still a certain challenge in this implementation. It is considered the relevance of a participatory educational process so that teaching-learning happens with quality in public schools, as they are essential agents in the education formation process, thus achieving a united team, more interactive responsible with the education professionals' school and with the formation of the student and the entire school community.

Keywords: Management; Democracy; Participative; Public.

\section{Resumen}

El énfasis de este estudio es reflexionar sobre la importancia de una gestión democrática y participativa en la Escuela Pública, en la que el administrador tiene un papel fundamental para hacer una escuela interactiva y agradable con el objetivo de una educación de calidad. Este artículo tiene como objetivo analizar la importancia de esta gestión para construir conocimiento de calidad en las escuelas públicas de la Baixada Fluminense. Se realizó una investigación bibliográfica y de campo, considerando los aportes de autores como Luck (2005 y 2017), Veiga (1997), Pereira (2018), Santos (2021), Fogaça (2021), entre otros. La inserción de una gestión democrático-participativa es todavía un proceso en curso, aunque es un sesgo de política pública, aún existe un cierto desafío en esta implementación. Se considera la relevancia de un proceso educativo participativo para que la enseñanza-aprendizaje ocurra con calidad en las escuelas públicas, ya que son agentes esenciales en el proceso de formación de la educación, llegando así a un equipo unido, más interactivo, responsable con los profesionales de la educación y con la escuela. la formación del alumno y de toda la comunidad escolar.

Palabras clave: Gestión; Democracia; Participativo; Público.

\section{Introdução}

O presente trabalho tem como tema a gestão democrática e participativa na Escola Pública enfatizando a importância para um ensino de qualidade. Nesta perspectiva construíram-se questões que nortearam este artigo:

- Uma gestão democrática e participativa interfere no ensino-aprendizagem de uma escola pública?

- Quais são as vantagens da participação da comunidade escolar na gestão?

A educação é a base para todos os contextos da sociedade, ela abrange um amplo benefício para o desenvolvimento social e econômico de um país. Sendo um crescimento constante de transformação, tem como principal objetivo promover a construção de personalidades morais autônomas, almejando o pleno exercício da cidadania, embasado nos sentidos democráticos de justiça, igualdade, equidade e participação ativa de todos os membros da sociedade na vida pública.

No cenário atual da educação no Brasil, bastante tem debatido sobre o nível de qualidade de ensino que é oferecido nas escolas, seja pública ou privada. Nesse âmbito, uma gestão democrática e participativa tem sua importância para uma possível mudança na realidade educacional e alcance dos objetivos, agindo positivamente no trabalho educacional. Segundo Luck (2017) para o trabalho educacional acontecer de forma significativa é recomendado que haja uma cooperação de ambas as partes dentro de uma comunidade escolar, partindo de um pressuposto de uma participação coletiva de todos os membros de todos os segmentos.

Onde a gestão é uma ação de mobilização da competência, por exemplo, a comunicação e a dinâmica do grupo. São competências que contribuem para uma gestão democrática e participativa, onde as pessoas compreendem que uma não tem mais poder do que a outra e sim todas unidas para uma educação melhor. O trabalho escolar é naturalmente um trabalho coletivo, visto que é necessário a participação conjunta de todos os seguimentos da comunidade escolar, tanto os que fazem parte direta quanto indiretamente no processo educacional.

\section{Metodologia}

Para alcançar os objetivos propostos, utilizou-se como recurso metodológico, a pesquisa bibliográfica, realizada a partir de análises de materiais disponíveis na internet e publicação literária. Além da pesquisa bibliográfica, a questão norteadora e seus resultados foram embasados em entrevistas feitas com gestores de escolas públicas de municípios da Baixada Fluminense - Rio 
de Janeiro de abordagem qualitativa, bem como de natureza exploratória. Tendo suporte metodológico autores como Luck (2005 e 2017), Veiga (1997), Pereira (2018), Santos (2021), Fogaça (2021) entre outros entre outros.

Ressalta-se que a educação é direito de todos e no que determina a Lei de Diretrizes e Bases da Educação - LDB, dentre um dos seus princípios que a educação pública possua uma gestão democrática e garantia de padrão de qualidade. Dando ênfase na importância de uma gestão democrática e participativa na escola para um alcance de objetivos educacionais. Assim tendo uma gestão que ouve variedades de opiniões para executar determinada decisão. Nesse contexto a escola compreende que a gestão precisa ser uma mediação, onde saiba mediar sobre seus recursos para atingir o seu objetivo que é uma educação transformadora.

Para uma educação de qualidade e transformacional, a comunidade escolar que são a equipe gestora, corpo docente e os responsáveis pelo educando cooperem em prol do principal propósito que é a aprendizagem do discente, por isso é relevante à participação de todos os envolvidos nas decisões que vão afetar essa aprendizagem, pois serão capazes de enxergar diferentes pontos de vistas de um mesmo objetivo, ou seja, do desenvolvimento do educando em sua totalidade e especificidade.

Ratificando o que dispõe na Lei de Diretrizes e Bases da Educação (1996, art. 14),

Art. 14 - Os sistemas de ensino definirão as normas da gestão democrática do ensino púbico na educação básica, de acordo com as suas peculiaridades e conforme os seguintes princípios.

I. Participação dos profissionais da educação na elaboração do Projeto pedagógico da escola:

II. Participação das comunidades escolar e local em conselhos escolares ou equivalentes.

Nesse contexto, o objetivo primordial desta análise é, pois, analisar qual a importância de uma gestão democrática e participativa para uma escola pública da Baixada Fluminense - RJ diante dos desafios que aparecem na realidade atual da educação no Brasil pandêmico.

\section{Resultados e Discussão}

A gestão democrática por via de um sistema participativo não é simples e resulta em muito debate acerca de deste levantado. Afim de embasar o estudo acerca da gestão participativa e democrática nas escolas públicas, foi realizado uma entrevista com gestores educacionais da Baixada Fluminense - RJ, que, ao responderem as questões básicas norteadoras desse trabalho, além de outras que se apresentaram relevantes, determinaram a direção pela qual a gestão escolar, voltada aos vários integrantes da educação na instituição pública tem seguido.

A entrevista abaixo, original e inédita, serve de material para coleta de dados do trabalho em questão, para se analisar a relação entre a realidade da educação e o conceito de educação democrática.

1. Uma gestão democrática e participativa interfere no ensino-aprendizagem de uma escola pública?

Gestor da Escola Municipal Duque de Caxias, Japeri: Com certeza, é de suma importância que o Gestor seja alguém envolvido com a comunidade e apto a ouvir e compreender as demandas necessárias dentro da escola.

Gestor da Escola Municipal Professora Enilza Barros dos Santos Chiconelli, Nova Iguaçu: Melhora sim, porque uma gestão séria e comprometida trabalha visando principalmente às melhorias pedagógicas reivindicadas pela comunidade escolar, não em prol da sua vontade.

Gestor da Creche Municipal Silvio Amâncio, Anchieta: Sim. 
Gestor da Escola Municipal Professor Gilvanei Pereira da Fonseca, Queimados: Sim, pois desta forma o ensino se torna plural e significativo, onde toda a equipe escolar, junto ao Conselho Escolar, acompanha e ajuda na tomada das decisões. Desta forma o desenvolvimento pedagógico alcança maior assertividade.

De acordo com Arruda (2020), a pandemia veio como uma reflexão sobre as dificuldades nas encontradas na educação remota, tal como no ambiente doméstico. Ressalta-se como é crucial a participação da comunidade escolar neste momento. Pois é necessário pensar sobre a sistematização do ensino e a qualidade oferecida nas escolas públicas.

Nas respostas contidas no primeiro questionamento acerca da interferência do conceito de gestão participativa, vê-se a compreensão dos gestores escolares acerca da gestão democrática. Ponto essencial para a execução desse conceito, já que, o gestor escolar, cargo com diversas funções e obrigações, deve se manter em contato com a comunidade e os ideais vigentes na instituição e nas políticas públicas que os englobam.

2. Quais são as vantagens da participação da comunidade escolar na gestão?

Gestor da Escola Municipal Duque de Caxias, Japeri: Creio que o entendimento de que a escola pública pertence aquela comunidade, o cuidado que deve ter com ela, a importância daquela escola na própria comunidade.

Gestor da Escola Municipal Professora Enilza Barros dos Santos Chiconelli, Nova Iguaçu: São muitas. Uma que eu considero muito importante é a descentralização do poder das mãos do gestor, o que acaba tornando a sua jornada mais leve, pois, quando todos participam da gestão, se pode colocar em prática a divisão de tarefas e todos se sentem responsáveis na tomada das decisões para que estas sejam colocadas em prática tão rapidamente, dependendo da tal urgência para a melhoria da qualidade da Educação que a escola oferece.

Gestor da Creche Municipal Silvio Amâncio, Anchieta: Ter toda equipe com um só pensamento de querer fazer o pedagógico acontecer onde não só um tem voz, mas todos contribui com um pouco para a engrenagem que é a educação não pare, também a parceria dos pais e comunidade que é muito importante. Pois a gestão precisa de todos para dar andamento no trabalho escolar que não se centraliza só no educar. Trabalhamos o social, emocional, intelectual e cultural então a gestão tem que ser democrática.

Gestor da Escola Municipal Professor Gilvanei Pereira da Fonseca, Queimados: Dividir as decisões e buscar solução para uma gestão de qualidade.

Paro (2012) afirma que os gestores devem garantir a transparência das ações administrativas e também devem garantir que as escolas ofereçam educação de alta qualidade. Conforme os requisitos legais, conformidade com as expectativas e as necessidades dos alunos de hoje, neste caso são pertinentes a participação de todos os membros da escola. Mostrando assim as vantagens observadas pelos gestores da Baixada Fluminense na participação da comunidade onde a instituição se insere. 
3. Como funciona, na prática, a gestão democrática nas escolas?

Gestor da Escola Municipal Duque de Caxias, Japeri: Infelizmente falta muita autonomia, mas pensando que antes a política estava dentro das escolas diariamente, creio que temos um avanço.

Gestor da Escola Municipal Professora Enilza Barros dos Santos Chiconelli, Nova Iguaçu: Na prática, a gestão democrática participativa acontece quando todos os participantes da vida diária da escola, pais, responsáveis, alunos, professores, funcionários, comunidade opinam, têm voz de forma igualitária e dividem as tarefas para os resultados desejados no PPP e as solicitações da comunidade são postas em prática, claro, dentro das possibilidades da escola. Às vezes, é possível, inclusive a comunidade se unir junto ao Conselho Escolar em busca de recursos para isso.

Gestor da Creche Municipal Silvio Amâncio, Anchieta: Ouvindo e fazer com que te ouçam, isso não é fácil pois lidamos com pessoas que pensam diferentes de nós. Então deve se fazer sempre reuniões para que os assuntos que vier para ser discutido chegue sempre a um consenso e a gestão e todos tenham sucesso.

Gestor da Escola Municipal Professor Gilvanei Pereira da Fonseca, Queimados: A gestão democrática começa com um Conselho Escolar participativo, fazendo parte das principais decisões, apoiando a gestão e defendendo sua comunidade. $O$ Grêmio Estudantil contribui também muito com a fala dos alunos sobre a escola.

Pode-se considerar um bom exemplo de funcionamento da gestão democrática no dia a dia escolar, o que foi posto pela gestora da Escola Municipal Professora Enilza Barros dos Santos Chiconelli, localizada no município de Nova Iguaçu, onde ela descreve a prática diária da gestão democrática nas escolas, citando a participação de alunos, responsáveis em geral, professores e outros funcionários do contexto escolar, além da comunidade, onde todos se envolvem para uma educação de qualidade, em busca de suprir as necessidades dos estudantes.

4. Qual o papel do Projeto Político Pedagógico (PPP) na gestão democrática?

Gestor da Escola Municipal Duque de Caxias, Japeri: O PPP é um documento elaborado por toda a comunidade, e é muito importante que ele não fique apenas no papel, sendo colocado em prática no dia a dia da escola.

Gestor da Escola Municipal Professora Enilza Barros dos Santos Chiconelli, Nova Iguaçu: Ele reconhece e legítima a participação construtiva e coletiva dos elementos da comunidade escolar, já que é o documento norteador das ações a seres desenvolvidas no estabelecimento de ensino. Na verdade, ele é nosso planejamento das ações que pretendemos pôr em prática na escola, levando em consideração a realidade da instituição.

Gestor da Creche Municipal Silvio Amâncio, Anchieta: Dar andamento a todo trabalho escolar de forma que o aprendizado e o conhecimento aconteçam naquela comunidade, através da construção do PPP da escola conhecemos a comunidade, suas culturas, necessidades, forças, fraquezas e baseado nessas informações adquiridas todo o trabalho é elaborado e posto em ação para que possamos como educadores ajudar a comunidade escolar daquela região. 
Gestor da Escola Municipal Professor Gilvanei Pereira da Fonseca, Queimados: O PPP fortalece todos os seguimentos da escola, mas para isso é preciso estar bem estruturado, com metas e objetivos bem definidos. Será um documento coletivo, pode até mudar a gestão, mas o que se deseja construir estará ali bem definido.

De acordo com Veiga (2006), "Projeto Político Pedagógico concebido como organização do trabalho da escola deve estar fundamentado nos princípios que deverão nortear a escola democrática, pública e gratuita"; assegurando, dessa forma, igualdade, qualidade, gestão democrática, liberdade e valorização do magistério.

5. Quais são os desafios atuais para a gestão participativa nas escolas públicas?

Gestor da Escola Municipal Duque de Caxias, Japeri: Infelizmente os responsáveis são muito ausentes da escola, alguns por causa do trabalho e outros por falta de interesse mesmo.

Gestor da Escola Municipal Professora Enilza Barros dos Santos Chiconelli, Nova Iguaçu: Creio que atualmente, o maior desafio para a gestão participativa seja fazer com que todos participem da gestão. Falo isso por experiência, pois percebo, que por mais que essa seja uma reivindicação da comunidade escolar, quando a convocamos para participar, uma boa parte dela acaba se esquivando. Lógico que não ponho a culpa nela poque este é um modelo novo de gestão para muitos, logo nem todos se percebem sujeitos capazes para opinarem e participarem da gestão. As pessoas ainda veem o gestor como o dono do poder, que só ele manda.

Gestor da Creche Municipal Silvio Amâncio, Anchieta: Os desafios são as próprias pessoas, pois conseguir uma equipe boa onde todos se ajudem e tem o pensamento de realizar um trabalho de qualidade é um grande desafio aqui na creche a equipe é muito boa. É claro que investir em formação continuada sempre é importante também, ter todo material pedagógico nas nossas mãos e ter muita compreensão e atendimento também. Hoje precisamos mais ainda de boa tecnologia.

Gestor da Escola Municipal Professor Gilvanei Pereira da Fonseca, Queimados: Conseguir pessoas participativas em todos os seguimentos para um Conselho Escolar atuante. Onde até a comunidade tenha seu representante, que acompanhe as decisões e resultados de forma constante visando o futuro dos alunos.

De acordo com as respostas do questionamento acima, vê-se que um dos maiores desafios é a participação plena dos integrantes da comunidade e da equipe em prol de um ensino democrático. Sobre esse assunto Dallari aborda:

Um aspecto interessante e grave, que é oportuno lembrar, é que um sistema político só é democrático quando as decisões são tomadas com liberdade e se respeita a vontade da maioria. Ora, quando muitos se negam a participar das decisões é inevitável que a tarefa de decidir fique nas mãos da minoria, ou seja, a omissão de muitos impede que se tenha um sistema democrático. (Dallari, 1983, p. 24)

E Dallari (1983) complementa que uma gestão participativa parte de um princípio de um planejamento em conjunto das atividades pertinentes de uma instituição, decisões que estão relativas a educandos e educadores, disciplinas empregadas e relações com a comunidade escolar. A participação na escola é relevante acontecer em vários segmentos escolares, seja de forma direta e indiretamente. 
6. Há participação da comunidade durante a pandemia?

Gestor da Escola Municipal Duque de Caxias, Japeri: Mínimo, mas existe. Algumas mães se oferecem para nos ajudar na entrega de cestas básicas.

Gestor da Escola Municipal Professora Enilza Barros dos Santos Chiconelli, Nova Iguaçu: Na nossa escola sim. Claro, dentro da medida do possível, alguns, considero poucos, mas participam. Como tem sido essa participação: trazem questões, sugestões, anotamos e dialogamos. Ano passado, inclusive, um grupo de mães nos procuraram e sugeriram que disponibilizássemos material impresso na Loja a lado para que elas tivessem acesso para xerocopiarem e levarem para seus filhos realizarem as atividades em casas.

Gestor da Creche Municipal Silvio Amâncio, Anchieta: Sim, ainda que não estão todos participando, mas um número razoável sim.

Gestor da Escola Municipal Professor Gilvanei Pereira da Fonseca, Queimados: Muito pouca em nossa comunidade. A falta de estrutura impede uma coletividade que seria fundamental no atual contexto. Aponto que as diferenças sociais se mostraram um impedimento grande na interação escola-comunidade, e uma urgência de políticas públicas

O direito à participação democrática nas instituições de ensino está garantido na Lei de Diretrizes e Bases da Educação de 1996, como se apresenta nos Art.14 - que dispõe sobre as normas da gestão democrática e os princípios que os sistemas de ensino seguem para defini-las - e Art. 15, no qual apresenta que "os sistemas de ensino assegurarão às unidades escolares públicas de educação básica que os integram progressivos graus de autonomia pedagógica e administrativa e de gestão financeira, observadas as normas de direito financeiro público". (BRASIL, 1996). Portanto, tal participação deve ser relevante a todo momento, inclusive durante a pandemia.

Nota-se, nas entrevistas, alguns fatores comuns às escolas públicas em sua relação com a democracia no âmbito escolar. Como a ideia de sua importância e ao mesmo tempo a falta de conhecimento acerca do assunto daqueles que englobam a equipe escolar, a comunidade e a família do estudante. Vê-se também que a participação dos responsáveis é uma necessidade, mas que existe em uma quantidade infimamente menor que o essencial ao avanço da gestão democrática.

Para Luck (2017) Democracia nada mais é do que um sistema político, onde o povo em sua maioria opina sobre a forma com que serão administradas ações praticadas pelo poder público, tendo poder de participação significativo. Um dos fatores primordiais da democracia é a liberdade de expressão, oportunidades de participação nas decisões tomadas que vão desde defender seus direitos a exercer seus deveres. Essa participação torna-se elemento essencial durante o desenvolvimento das políticas públicas que englobam a educação.

De acordo com o Plano Nacional de Educação (PNE), estabelecido pela Lei. 13.005/2014, elaborado para fazer-se cumprir o Art. 214 da Constituição Federal, estão definidos como objetivos principais a erradicação do analfabetismo e universalização do atendimento escolar, eixos norteadores que a gestão democrática e participativa precisa ter como foco para que haja um desenvolvimento pleno do educando e consequentemente da comunidade escolar.

Em alguns países a democracia aconteceu de forma rápida, como Espanha e Portugal, mas esta luta por uma sociedade mais democrática é antiga, no Brasil essa ação foi adquirida em longo prazo, onde passou por ditadura militar e depois surgindo um governo democrático. Firmando a atual Constituição Federal de 1988, conhecida também como Constituição Cidadã, trazendo consigo avanços democráticos para sociedade brasileira, como exemplo, eleições diretas, no qual a eleição é ocorrida 
de forma que os ocupantes dos cargos legislativos e executivos são escolhidos através do voto dos eleitores. Essas eleições entraram em vigor nos anos de 1945-1964, ano em que ocorreu o golpe militar.

Segundo Serpa (2011) para que o Brasil contemple uma melhora em seu sistema educacional é necessário que sejam aprimorados os critérios para a escolha e manutenção da interação da direção escolar com a comunidade, pois a mesma afeta todo o funcionamento do Projeto Político Pedagógico, como foi relatado pelos gestores entrevistados das escolas públicas da Baixada Fluminense, principalmente enfrentando uma pandemia mundial.

De acordo com Vianna (1986) no âmbito educacional, a luta dos educadores era contra uma educação autoritária. Por volta dos anos 60-80 surgiram discussões a respeito de assuntos pedagógicos em busca de uma educação mais igualitária e a democratização da gestão. Complementa Vianna (1986) "experiências isoladas de gestão colegiada de escolas sempre existiram, mas não tiveram um impacto maior sobre os sistemas de ensino". A escola brasileira passou por diversas transformações e teve algumas tendências pedagógicas até chegar ao que se vivencia em sua grande maioria, uma escola que busca igualdade, inclusão e voz de opinião aos envolvidos (professores, gestores, funcionários da escola, responsáveis e alunos).

Para haver uma gestão democrática é necessária a compreensão de que o processo precisa agir em conjunto com diversas áreas e pensamentos. Veiga (1997), assim ressalta que, a teoria e prática e/ou concepções e agir precisam ser simultâneas e complementares, extinguindo o pensamento de uma prática sem base teórica e uma teoria sem sua execução. Então o trabalho dos educadores visa a busca por um processo completo e dinâmico. A gestão democrática e participativa que se deseja em uma instituição escolar é uma construção social histórica, que cria raízes na formação plena do aluno, como ser humano, cidadão ético e autônomo, pronto para viver em sociedade, baseando-se firmemente nas políticas acerca do convívio e dos direitos e deveres vigentes na Constituição de 1988.

Argumenta Mendonça (2001), que quando se debate sobre democracia na escola, geram dúvidas diante disso, pois uma porcentagem dos profissionais não acredita existir ou que não possa existir, mas pelo contrário, não significa que é algo impossível de acontecer. Na atualidade ver-se o diretor com poder nas mãos, quem possui a palavra de ordem. Entretanto esse poder quando usado para impor apenas interesses do mesmo, se torna uma figura autoritária dentro da escola, onde os interesses do educando não são levados em consideração, gerando falta de motivação nos estudos, uma equipe desunida e competitiva entre si, sem refletir sobre o real objetivo que é a qualidade do ensino. Para que se tenha uma postura adequada do gestor em relação às políticas públicas escolares é necessário grande participação do mesmo, para que ele tenha total visão da amplitude de suas obrigações para com o meio. Nessa postura, deve-se citar, além do comprometimento do gestor, a divisão de responsabilidade, transparência das contas em que se utiliza dinheiro público, criação da cultura de participação comunitária, garantindo que os processos tenham como referência a legislação vigente e seus documentos, bem como as decisões tomadas em reuniões e conselhos, entre outras atitudes essenciais. Dessa forma, os representantes escolares devem defender os interesses coletivos, compartilhando as percepções e pensamentos pois, sem a liderança correta, a escola deixaria de ser participativa para ser uma instituição com poder monopolizado.

Hora (1994, p.51), afirma que o principal método de gestão participativa é o planejamento participativo, que se baseia em visões deliberadas de futuro. Diferentes partes da organização têm suas próprias visões, valores e aspirações. Essas partes têm poder de decisão e formularão uma política. Realizar debate, reflexão, problematização, pesquisa, aplicação, avaliação e reformulação de mudanças na própria organização, a longo prazo.

Por isso para Luck (2017) a participação vem de um ato consciente dos membros envolvidos, onde influenciam as decisões a serem tomadas, reconhecem que possuem um papel importante no poder de planejar e decidir determinadas ações pedagógicas. Com essa autonomia de intervir no mecanismo de gestão, dando-lhes oportunidades de modificar no seu próprio trabalho educacional e desenvolvimento pleno do educando. Segundo Heloísa Luck (2007), uma instituição escolar universitária é um mecanismo de gestão escolar que visa auxiliar a tomada de decisões em todas as áreas de suas atividades e encontrar 
diferentes meios para atingir o objetivo de ajudar em diversos aspectos a estabelecer a educação. Para que pais, professores e funcionários possam interagir e participar.

Como aponta Luck (2005) frisa-se que um órgão colegiado é relevante para que haja representações dos componentes e de suas concepções, trabalhando em conjunto para uma gestão participativa e democrática. Em contra partida, essa busca por uma gestão participativa na escola pública não é tão fácil como na teoria, pois os responsáveis são em sua maioria de classe baixa, onde trabalham com carga horária extensa e não lhe permitem participar de reuniões e acompanhamento do educando na escola.

Para Moreira (2020), um dos meios que a escola encontrou de manter a participação da comunidade é por meio dos conselhos escolares. A criação desse conselho se dá pelo interesse de uma instituição democrática e participativa, onde ele se situaria entre o estado e a sociedade, buscando canais de participação popular pelo bem público. Servindo assim, para fazer valer o que está escrito, sem impor uma vontade individual à instituição, mas sim de um coletivo, democraticamente. A composição desses conselhos apresenta diversidade em seus participantes, garantindo que pontos de vistas das várias vertentes da equipe escolar sem considerados de acordo com a escola e com o ideal escolar da comunidade onde a instituição está inserida. Pra tal, é necessário total participação, com professores, funcionários, responsáveis etc. Os conselhos escolares se originaram no fim da década de 1970, com as lutas pela redemocratização, reivindicando assim, participação de setores variados. Lembrando que, as legislações atuais, que fundamentam as ações dos conselhos escolares, são consequência de movimentos populares direcionados por movimentos sociais das décadas anteriores. Como exemplo pode-se citar a própria Constituição Federal de 1988, A Lei de Diretrizes e Bases da Educação Nacional e o Plano Nacional de educação.

Nas palavras de Santos (2021) abordar sobre esse assunto gera uma sensação de eficácia em curto prazo, porém há desafios onde é necessário traçar avanços para transformar o que foi planejado na teoria em prática. Esses desafios constituem desde motivação dos professores a presença dos responsáveis no conselho de classe' no qual é órgão colegiado de natureza consultiva e deliberativa em assuntos didático-pedagógicos, fundamentado no Projeto Político Pedagógico da escola e no Regimento Escolar. Diante disso, o gestor tem função significativa para que haja na escola pública um ambiente agradável e interativo entre funcionários, responsáveis e alunos. Esforçando-se para realizar um exercício pedagógico grupal.

E esta ação participativa ainda é nova para alguns diretores, então por esse desconhecimento se torna uma figura autoritária, que toma decisão sozinha, sem conhecer a realidade e experiências dos demais membros do espaço escolar. É importante compreender que existe uma diferença muito grande entre a realidade proclamada e a realidade que está no dia a dia da instituição, e cabe ao gestor, com seu trabalho nos âmbitos pedagógico e administrativo, realizar a mediação entre esses fatores, de forma a criar uma vertente democrática da educação.

Como aponta Paz (2021) a inserção de uma gestão democrático-participativa ainda é um processo em andamento, mesmo sendo um viés da política pública, ainda há certo desafio nesta implantação. Em que há contrariedade que dificultam esta gestão, como o autoritarismo, as relações Estado-escola e falta de qualificação dos profissionais de educação. E sobre esses obstáculos, Mendonça (2001) afirma que a própria sociedade é a legítima beneficiária da gestão democrática da educação pública e está determinada pelas autoridades a resistir às iniciativas nacionais. Da mesma forma, a atitude de mediação, o desinteresse ou a consciência da importância dos processos democráticos, muitas vezes tornam a aplicação de mecanismos de gestão participativa um foco intransponível.

Como cita Moreira (2020) os gestores surgiram como um fator fundamental para superar esses obstáculos, pois será ele que ficará à frente para gerir recursos a serem utilizados dentro da escola, gerir os processos, se os objetivos desses processos estão sendo alcançados e a gestão de pessoas, onde ele precisa ter a preocupação de que a comunidade escolar esteja se interagindo de forma harmoniosa, apoiar esses profissionais, além de assessorar e motiva-las. 
Contribuindo também para uma gestão pedagógica que envolve currículo e ação docente e contribuindo com uma gestão da sala de aula para avaliar e reforçar a aprendizagem da escola. Enfatizando a participação efetiva da comunidade escolar dessas decisões. Levando em conta a realidade daquela região e do aluno, que é o principal objetivo.

\section{Considerações Finais}

Diante dos argumentos mencionados junto aos autores e suas ideias, conclui-se que dentro de um ambiente escolar é importante uma gestão democrática e participativa, enfatizando a escola pública, onde os componentes são geradores de críticas construtivas para obter um ensino eficaz e seguir o que dispõe a legislação brasileira.

A democracia e a participação são agentes primordiais no processo de formação da educação de qualidade na escola, alcançase assim uma equipe unida, responsáveis mais interativos com os profissionais de educação da escola e com a formação do educando. Participando desde as decisões a serem tomadas como o cotiando do aluno. Assim sendo necessário o reconhecimento das mudanças necessárias para a transformação que se faz necessária no sistema educacional brasileiro.

Diante desta consideração final desta análise acerca da gestão democrática nas escolas públicas da Baixada Fluminense em meio a uma pandemia, pretende-se expandir o processo de investigação em pesquisas futuras e aprofundar o pano de fundo histórico para uma gestão de qualidade e eficaz. Portanto, a complexidade da pesquisa iniciada neste trabalho é complementada pelas condições de trabalho com os gestores, a relação entre os processos de ensino e aprendizagem e outros fatores que afetam a qualidade existente nas escolas públicas.

\section{Referências}

Arruda, E. P. (2020). Educação remota emergencial: elementos para políticas públicas na educação brasileira em tempos de Covid-19. EmRede-Revista de Educação a Distância, 7(1), 257-275.

Brasil, Lei de nº 9394/1996, dezembro de 1996. Estabelece as diretrizes e bases da educação nacional.http://www.planalto.gov.br/Ccivil_03/leis/L9394.htm

BRASIL. Constituição (1988). Constituição da República Federativa do Brasil. Brasília.

Dallari, Dalmo de Abreu (1983). O que é participação política. Editora Brasiliense.

Estrela, C. (2018). Metodologia Científica: Ciência, Ensino, Pesquisa. Editora Artes Médicas.

Flores, Sandra Nogueira. Cordeiro, Rogério Soares. (2021). A importância da articulação família e escola na formação do aluno em uma perspectiva da Educação do Campo. Society and Developmente, v.10, n.4.

Fogaça, Priscila Carvalho; Arossi, Guilherme Anzilero; Hirdes, Alice (2021). Impacto do isolamento social ocasionado pela pandemia COVID-19 sobre a saúde mental da população em geral: Uma revisão integrativa. Society and Developmente, v.10, n.4.

Gomes, R. (2001). A análise de dados em pesquisa qualitativa. In: Minayo, M. C. de S. (org.). Pesquisa social: teoria, método e criatividade. (33a ed.), Vozes Hora, Dinair Leal. (1994) Gestão democrática na escola: artes e ofícios da participação coletiva. São Paulo: Papirus.

Koche, J. C. (2011). Fundamentos de metodologia científica. Petrópolis: Vozes. http://www.brunovivas.com/wpcontent/uploads/sites/10/2018/07/K\%C3\%B6che-Jos\%C3\%A9-Carlos0D0AFundamentos-de-metodologia-cient\%C3\%ADfica-_teoriada0D0Aci\%C3\%AAncia-e-inicia\%C3\%A7\%C3\%A3o-\%C3\%A0-

pesquisa.pdfhttps://repositorio.ufsm.br/bitstream/handle/1/15824/Lic_Computacao_Metodologia-Pesquisa-Cientifica.pdf?sequence=1]

Luck, Heloisa. (2017) A Gestão Participativa na Escola. Rio de Janeiro: Vozes.

Luck, Heloísa. (2005) A escola participativa - O trabalho do gestor escolar. $3^{\text {a }}$ ed. Petrópolis, Vozes.

Ludke, M. \& Andre \& M. E. D. A. (2013). Pesquisas em educação: uma abordagem qualitativa. São Paulo: E.P.U. 5.5) Yin, R.K.

Mendonça, (2001) Estado Primordial e gestão democrática do ensino público no Brasil. Educação e Sociedade, SP, v.22, n 72 , p. 94. ago.

Moreira, J. A.\& Schlemmer, E. Por um novo conceito e paradigma de educação digital online. Revista UFG, v. 20, 2020

Oliveira, Ranyelly Rodrigues de \& Silva, Ana Paula Bispo da. (2021) A formação conceitual sob a perspectiva teórica de Vygotsky, Leontiev e Galperin. Society and Developmente, v.10, n.4. 
Research, Society and Development, v. 10, n. 6, e57010616072, 2021

(CC BY 4.0) | ISSN 2525-3409 | DOI: http://dx.doi.org/10.33448/rsd-v10i6.16072

Paz, Mário Sérgio de Oliveira; Almeida, Núbia Regia de Almeida; Araújo, Jaqueline Pereira de; Ramos, Ayrton Moraes. (2021). Envolvimento dos discentes nas atividades escolares em tempos de pandemia do COVID-19: Ações desenvolvidas pelo o IFPA - Campus Paragominas. Society and Developmente, v.10, n.3.

Pereira A. S. et al. (2018). Metodologia da pesquisa científica. [free e-book]. Santa Maria/RS. Ed. UAB/NTE/UFSM.

Santos, Helma Costa dos; Ferreira, Margarida Elisa Ehrhart; Souza, Maria Clécia Almeida de. (2021). Adequação da proposta pedagógica para o ensino remoto: A experiência doa $1^{\circ}$ anos da Escola Classe 304 Norte. Society and Developmente, v.10, n.4.

Serpa, D. (2011) Como os gestores são escolhidos em outros países. Disponível em: https://gestaoescolar.org.br/conteudo/507/como-os-gestores-saoescolhidosem-outros-paises. Acesso em maio de 2021.

Silva, K. K. A. \& Behar, P. A. (2019). Competências digitais na educação: uma discussão acerca do conceito. Educação em Revista, 35(209940), 1-32.

Veiga, I. P. A. (1997) (Org.) Projeto Político Pedagógico - Uma Construção Possível. Campinas, SP: Papirus.

Vianna, I. O. A. (1986) Planejamento Participativo na Escola. São Paulo: EPU. 